\title{
Molten Salt Synthesis of Calcium Hydroxyapatite Whiskers
}

\author{
A. Cüneyt Taş*, \\ Department of Metallurgical and Materials Engineering, Middle East Technical University, Ankara 06531, Turkey
}

\begin{abstract}
Calcium hydroxyapatite (HA) whiskers and crystals were produced by the route of molten salt synthesis. The effects on whisker morphology of chosen flux, flux-to-HA ratio, synthesis temperature, and reaction time were investigated. The thermal stabilities of the produced whiskers were tested at $1300^{\circ} \mathrm{C}$ in an air atmosphere. A tentative $\mathrm{X}$-ray diffraction pattern was proposed for the HA whiskers. Molten salt synthesis with a $\mathrm{K}_{2} \mathrm{SO}_{4}$ flux was found to be a simple and sturdy technique for manufacturing short $(\leq 60 \mu \mathrm{m})$ HA whiskers in the temperature range from $1080^{\circ}$ to $\sim 1200^{\circ} \mathrm{C}$. The alternative use of fluxes such as $\mathrm{KCl}, \mathrm{KBr}, \mathrm{CaCl}_{2}$, or $\mathrm{Na}_{2} \mathrm{SO}_{4}$, rather than $\mathrm{K}_{2} \mathrm{SO}_{4}$, over the temperature range $850^{\circ}-1000^{\circ} \mathrm{C}$ resulted in the formation of large $(\sim 25 \mu \mathrm{m})$ single crystals of HA.
\end{abstract}

\section{Introduction}

$\mathrm{C}$ AlCiUM hydROXYAPATITE $\left(\mathrm{Ca}_{10}\left(\mathrm{PO}_{4}\right)_{6}(\mathrm{OH})_{2}\right)$ is one of the most biocompatible ceramics, because of its significant chemical and physical resemblance to the mineral constituents of human bones and teeth. For load-bearing orthopedic and dental applications, densified HA ceramics are needed. However, dense HA ceramics manufactured by using synthetic HA powders have always exhibited a low fracture toughness, of $\sim 1 \mathrm{MPa} \cdot \mathrm{m}^{1 / 2}$, in contrast to the values observed for human bones, in the range 2-12 $\mathrm{MPa} \cdot \mathrm{m}^{1 / 2} \cdot 1$

Reinforcement by whiskers has been considered as a way of improving the fracture toughness of pure HA bioceramics; thus, whiskerlike or needlelike crystals of HA have been synthesized in recent years, mainly by the hydrothermal method or precipitation routes. ${ }^{2-9}$ However, the whiskers synthesized by these methods ${ }^{4-6}$ suffer from nonstoichiometry (i.e., calcium deficiency) and have low thermal stability, i.e., they partially decompose into a $\beta$-TCP phase (5-35 vol\% TCP), even after $1 \mathrm{~h}$ of heating at $1100^{\circ} \mathrm{C}$. Moreover, Suchanek et al. ${ }^{5}$ have reported that, for HA composite ceramics reinforced with hydrothermally synthesized HA whiskers ( $\sim 30$ vol\% whiskers), the whiskers disappear within the HA matrixes at sintering temperatures $\geq 1000^{\circ} \mathrm{C}$ and turn themselves into large, equiaxed grains. ${ }^{6}$ The fracture toughness values of these samples have been reported ${ }^{5}$ to remain only in the modest range of 1.4-2.0 $\mathrm{MPa} \cdot \mathrm{m}^{1 / 2}$.

Molten salt synthesis (MSS) is reported to be one of the simplest techniques for preparing ceramic powder bodies with whiskerlike, needlelike, or platelike morphology and, as well, complex stoichiometry. ${ }^{10}$ The MSS technique is based on the use of low-melting solvents, such as alkali chlorides, sulfates, carbonates, or hydroxides, as the medium of reaction for the ceramics. The literature on molten salt synthesis is quite extensive and, to name just a few cases, this technique has been used (with different alkali salts) to prepare ferrites, ${ }^{10}$ titanates, ${ }^{11-13}$ niobates, ${ }^{14-17}$

P. W. Brown-contributing editor

Manuscript No. 188607. Received April 24, 2000; approved September 19, 2000. ${ }^{*}$ Member, American Ceramic Society.

${ }^{\dagger}$ Present address: Max-Planck-Institut für Metallforschung, Heisenbergstrasse 5, Stuttgart D-70569, Germany. mullite, ${ }^{18}$ aluminum borate, ${ }^{19,20}$ wollastonite, ${ }^{21}$ and carbonated apatite $\left(\mathrm{Ca}_{9.8}\left(\left(\mathrm{PO}_{4}\right)_{5.6}\left(\mathrm{CO}_{3}\right)_{0.4}\right)\left(\mathrm{CO}_{3}\right)\right.$, by using a high-melting flux of $\left.\mathrm{CaCO}_{3}\right){ }^{22}$ The selection of the salt in MSS is critical for obtaining desirable powder morphology and characteristics. There are two major requirements for the selection of a salt: ${ }^{16}$ First, the melting point of the salt should be low and appropriate for the synthesis of the required phase; second, the salt should have sufficient aqueous solubility that it will be eliminated easily by simple washing, after synthesis.

In the present study, we used submicrometer-sized HA powders synthesized by a previous method ${ }^{23-25}$ as the starting material for the MSS method. The effects on whisker morphology of the alkali salt chosen, the temperatures/times of synthesis, and the saltto-HA powder ratio used were studied. To our knowledge, this report is the first describing the successful preparation of monodisperse $\mathrm{HA}$ whiskers, using $\mathrm{K}_{2} \mathrm{SO}_{4}$ salt, by the simple technique of MSS.

\section{Experimental Procedure}

\section{(1) Preparation of HA Powders}

The single-phase calcium hydroxyapatite powders used as the starting material for the MSS of the HA whiskers were synthesized as follows. ${ }^{23-25}$ (The following procedure is the derivative of a route described earlier by Hayek and Newesely, ${ }^{26}$ Moreno et al.,${ }^{27}$ and Jarcho et ll $^{28}$ ) A $3 \mathrm{~mL}$ aliquot of $0.1 \mathrm{~g} / \mathrm{L}$ methyl cellulose solution (99\% purity, Sigma-Aldrich Corp., St. Louis, MO) was mixed (to act as a dispersant) with $1440 \mathrm{~mL}$ of deionized water. Next, $0.152 \mathrm{~mol}$ of $\mathrm{Ca}\left(\mathrm{NO}_{3}\right)_{2} \cdot 0.4 \mathrm{H}_{2} \mathrm{O}(99.8 \%$ purity, Merck, Darmstadt, Germany) was dissolved in the above-described solution. Then, $0.090 \mathrm{~mol}$ of $\left(\mathrm{NH}_{4}\right)_{2} \mathrm{HPO}_{4}(99.8 \%$ purity, Merck) was dissolved in that solution. Following that step, $115 \mathrm{~mL}$ of $24 \mathrm{vol} \%$ $\mathrm{NH}_{4} \mathrm{OH}$ was added, in its entirety, to the above-described opaque solution. The solution was heated and vigorously stirred at $60^{\circ}-70^{\circ} \mathrm{C}$ for $3 \mathrm{~h}$, on a hot plate. The precipitates that formed were recovered from the supernatant, by filtering, and washed five times with deionized water. The filtrates were dried at $100^{\circ} \mathrm{C}$ overnight. Finally, the HA precursors were calcined in an air atmosphere at $1000^{\circ} \mathrm{C}$ for $6 \mathrm{~h}$ and then lightly ground by hand, with an agate mortar and pestle.

\section{(2) Synthesis of $\mathrm{HA}$ Whiskers}

$\mathrm{HA}$ powders calcined at $1000^{\circ} \mathrm{C}$ were dry-mixed in an agate mortar with potassium sulfate $\left(\mathrm{K}_{2} \mathrm{SO}_{4}, 99.9 \%\right.$ purity, Merck) at $\mathrm{K}_{2} \mathrm{SO}_{4}$-to-HA weight ratios in the range 1.2-3.0, for a total sample weight of $2 \mathrm{~g}$. In several experiments, the $\mathrm{K}_{2} \mathrm{SO}_{4}$ (melting point $\left.(\mathrm{MP})=1069^{\circ} \mathrm{C}\right)$ flux was replaced by sodium sulfate $\left(\mathrm{Na}_{2} \mathrm{SO}_{4}\right.$, $\left.\mathrm{MP}=884^{\circ} \mathrm{C}\right)$, calcium chloride $\left(\mathrm{CaCl}_{2}, \mathrm{MP}=782^{\circ} \mathrm{C}\right)$, potassium chloride $\left(\mathrm{KCl}, \mathrm{MP}=771^{\circ} \mathrm{C}\right)$, or potassium bromide $(\mathrm{KBr}, \mathrm{MP}=$ $734^{\circ} \mathrm{C}$ ). The mixtures, as loose powder compacts, were then placed into clean alumina boats with a volume of $7.5 \mathrm{~cm}^{3}$ and set inside a box furnace. The samples were heated from the ambient to the peak temperature of whisker synthesis at a rate of $5^{\circ} \mathrm{C} / \mathrm{min}$. Following soaking times ranging from 0.5 to $3.5 \mathrm{~h}$ at the peak temperatures $\left(850^{\circ}-1190^{\circ} \mathrm{C}\right)$, the samples were cooled naturally to room temperature within the shut-off furnace. The single-crystal whiskers or particles were separated from the solidified mass by washing the mass several times with hot $\left(\sim 90^{\circ} \mathrm{C}\right)$ deionized water. 
Washing was repeated until the specific conductance of the decanted liquid fell to $<2.4 \mu \mathrm{S}$, measured ${ }^{11}$ using a conductance meter (Model No. Digi610, WTW, Weilheim, Germany), knowing that the conductance of deionized water was $1.4 \mu \mathrm{S}$. Finally, the washed whiskers were dried in an oven, at $100^{\circ} \mathrm{C}$, overnight.

\section{(3) Investigation of Thermal Stability of Whiskers}

The morphology and phase stability of the HA whiskers after heating (with heating/cooling rates of $5^{\circ} \mathrm{C} / \mathrm{min}$ ) at $1300^{\circ} \mathrm{C}$ for $9 \mathrm{~h}$, as a loose powder compact, in an air atmosphere, were evaluated by scanning electron microscopy (SEM), X-ray diffractometry (XRD), and Fourier transform infrared spectrometry (FT-IR).

\section{(4) Sample Characterization}

The phase constitution of the whiskers was analyzed by XRD (Model No. D-5000, Siemens Aktiengesellschaft, Karlsruhe, Germany) and $\mathrm{Cu} K_{\alpha}$ radiation $(40 \mathrm{kV}, 30 \mathrm{~mA})$. For lattice-parameter determinations, a scan rate of $0.2^{\circ} 2 \theta / \mathrm{min}$ (over the range $10^{\circ}-70^{\circ}$ $2 \theta$ ), using a silicon external standard to correct for systematic errors, was used, along with the Appleman Least-Squares Refinement Program. ${ }^{29}$ The morphologic and semiquantitative elemental distribution information on the samples were obtained by SEM (Model No. DSM 982-Gemini, Karl Zeiss, Inc., Oberkochen, Germany), and by energy dispersive X-ray spectroscopy (EDS), respectively. Quantitative chemical analyses were performed by inductively coupled plasma atomic-emission spectroscopy (ICPAES; Model No. JY-70Plus, Jobin Yvon S.A., Longjuveau, France). An FT-IR spectrophotometer (Model No. IFS66, Bruker, Karlsruhe, Germany) was used to measure the infrared transmission spectra of the whiskers, after the whiskers had been mixed with dry $\mathrm{KBr}(1 \mathrm{wt} \%)$, to form pellets.

\section{Results and Discussion}

The SEM micrographs given in Fig. 1 show the morphology of the starting HA powders used in this study in molten salt whisker synthesis. The chemically precipitated HA precursors, following filtration from the mother liquor and $100^{\circ} \mathrm{C}$ drying, consisted of nanosized, but aggregated, particles, as depicted in Fig. 1(a). These precursors were poorly crystalline, but not completely amorphous. Their crystallization behavior, as a function of calcination temperature, has been published elsewhere. ${ }^{25}$ Figure 1(b) shows the microstructure of the same powders after calcination (as a loose powder compact) in air at $1000^{\circ} \mathrm{C}$ for $6 \mathrm{~h}$. The average particle size was $\sim 100 \mathrm{~nm}$. Calcined HA powders were determined, by XRD, to be "single-phase" HA (with only a small amount of $\mathrm{CaO}$, not readily detectable by rapid XRD scans) with a $\mathrm{Ca} / \mathrm{P}$ atomic ratio (measured by ICP-AES) of $1.68 \pm 0.01 .^{24,25} \mathrm{This} \mathrm{Ca} / \mathrm{P}$ ratio in the calcined powders was intentionally adjusted to that value by the specific $\mathrm{Ca} / \mathrm{P}$ ratio used in the chemical precipitation of precursors. The XRD pattern of the calcined $\left(1000^{\circ} \mathrm{C}, 6 \mathrm{~h}\right) \mathrm{HA}$ powders is shown as the bottom trace of Fig. 2.

HA powders precalcined at $1000^{\circ} \mathrm{C}$ (to ensure that the starting materials consisted of single-phase hydroxyapatite) were then mixed with the alkali salts listed in Table I for MSS. $\mathrm{K}_{2} \mathrm{SO}_{4}$ was first $^{20}$ tested as the fluxing agent in MSS runs at four different salt-to-HA weight ratios and four different temperatures. The samples, labeled W1-W12 (see Table I), all produced single-phase HA whiskers. The XRD pattern of the W4 sample is shown by the middle trace of Fig. 2. The same XRD trace was observed for all of the samples, labeled as Wxx in Table I. That trace represents the characteristic XRD pattern for calcium hydroxyapatite, although the intensities of the 211 and 300 planes are changed, because of whisker orientation. This result was also the case for previously reported $^{3-6}$ hydrothermally synthesized HA whiskers, and the whiskers were apparently elongated along the $c$ axis. Moreover, all of the HA whiskers of samples W1-W12 were totally transparent, according to examination by optical microscopy.
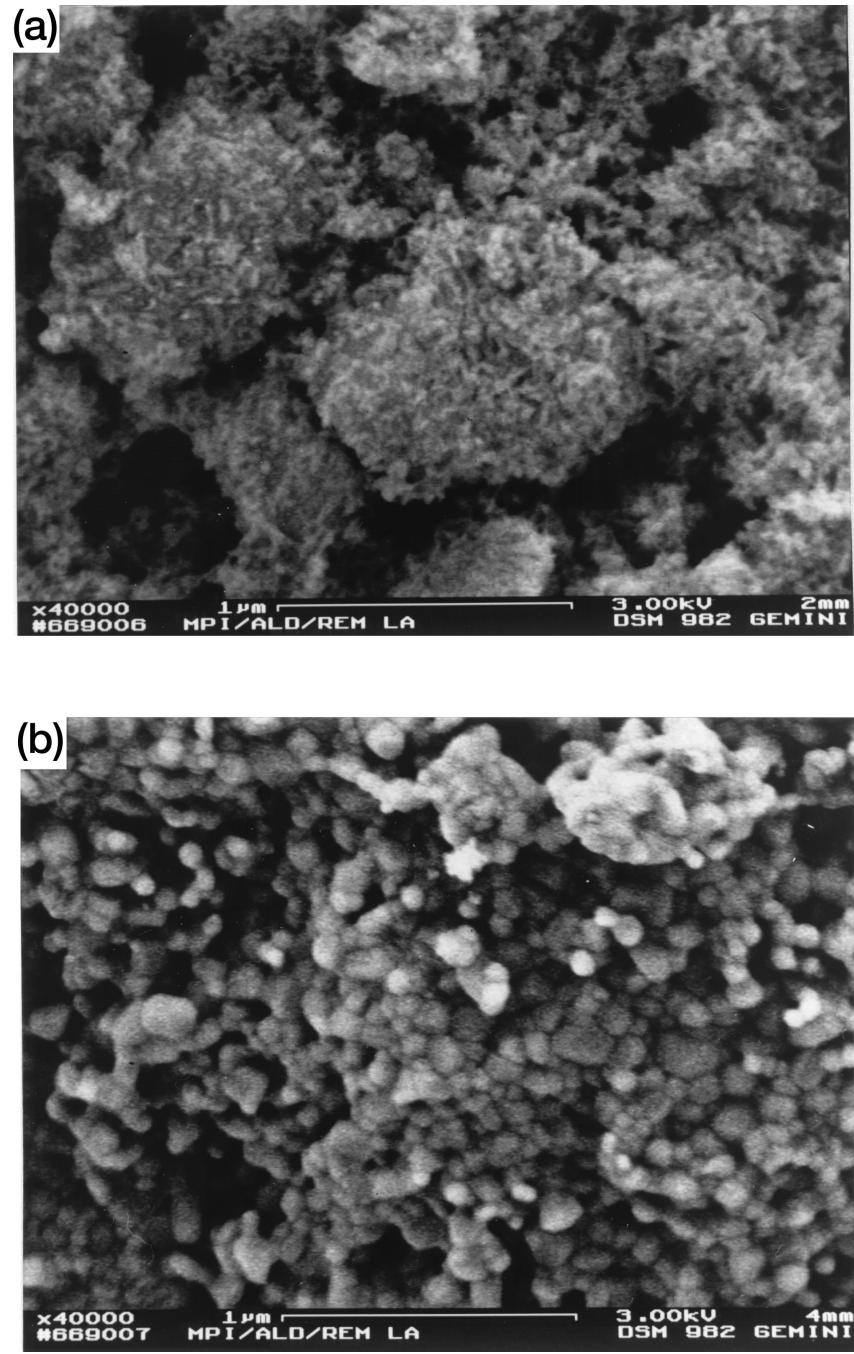

Fig. 1. SEM micrographs of HA powders at (a) $100^{\circ}$ and (b) $1000^{\circ} \mathrm{C}$.

ICP-AES analyses performed on the Wxx samples showed the presence of $0.55-0.60 \mathrm{wt} \%$ potassium in the whiskers, regardless of the salt-to-HA ratios and synthesis temperatures/times used in this study. Potassium was expected to substitute the calcium sites of the HA lattice. No sulfur was detected in the whiskers by the ICP-AES analyses. Thus, the crystals produced in the present study could not be regarded as "pure" calcium hydroxyapatite whiskers, and they had the typical formula of $\mathrm{Ca}_{1-x} \mathrm{~K}_{x}$ $\left(\mathrm{PO}_{4}\right)_{6}(\mathrm{OH})_{2-x}$, where $x$ varied between 0.140 (i.e., $0.55 \mathrm{wt} \%$ ) and 0.155 (i.e., $0.60 \mathrm{wt} \%$ ).

However, human bones and tooth enamel are also known ${ }^{30}$ to contain significant quantities of alkali and alkali earth cations, such as $\mathrm{Na}^{+}, \mathrm{K}^{+}$, and $\mathrm{Mg}^{2+}$. The sum of these three ions in human bones reaches $\sim 1.3 \mathrm{wt} \%$, whereas, in enamels, the same figure has been reported ${ }^{30}$ to be $\sim 1 \mathrm{wt} \%$. On the other hand, the $\mathrm{Ca} / \mathrm{P}$ molar ratio of the present MSS whiskers was found, by ICP-AES analyses, to be $1.64 \pm 0.01$. These whiskers may also be regarded as calcium-deficient, in comparison with stoichiometric HA, which has a $\mathrm{Ca} / \mathrm{P}$ molar ratio of 1.667 . However, the $\mathrm{Ca} / \mathrm{P}$ ratios of dental enamel and human bones are known ${ }^{30}$ to be 1.62 and 1.65 , respectively.

The lattice parameters of the W4 whiskers (middle XRD trace in Fig. 2) were determined, by least-squares analysis, ${ }^{29}$ to be $a=$ 9.4189 and $c=6.8827 \AA$. The hexagonal unit cell (of the space group of $P 6_{3} / \mathrm{m}$ ) had a cell volume of $528.79 \AA^{3}$. The lattice parameters of these whiskers resembled those reported previous$1 \mathrm{y}^{30}$ for the apatite of human bones, although these whiskers and human bones do not have the same chemical constitution. The 


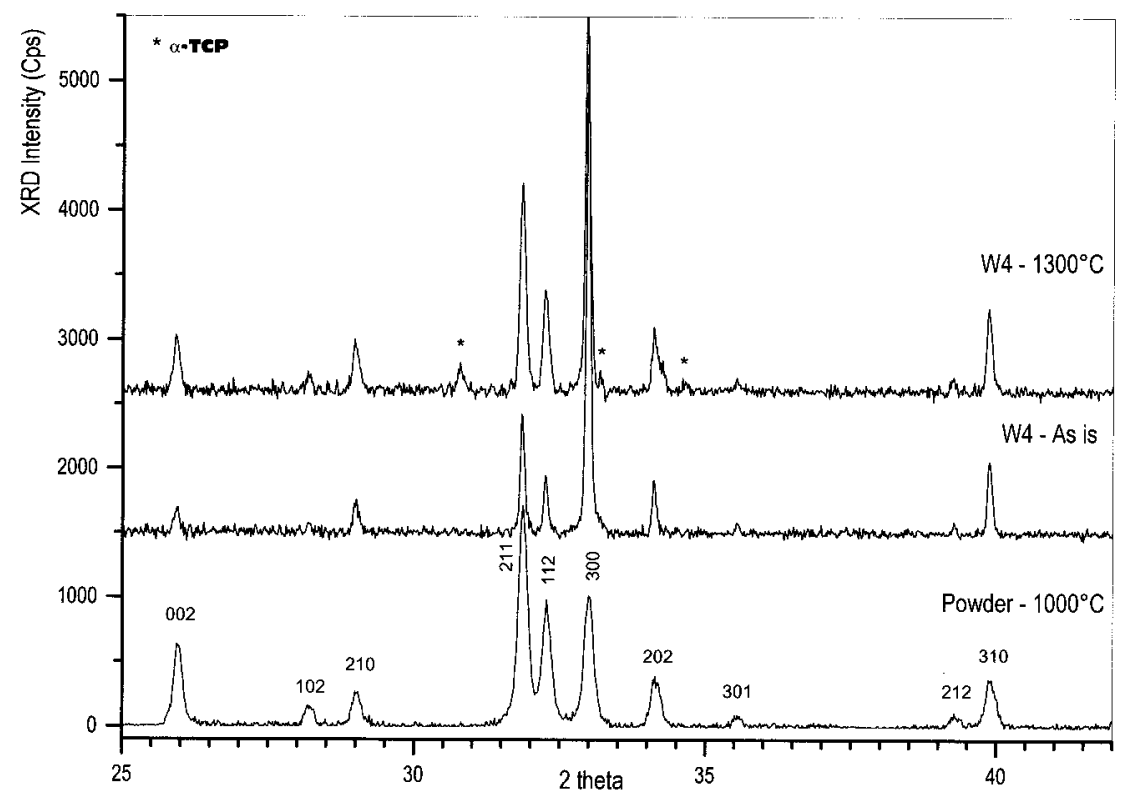

Fig. 2. XRD patterns of HA powders and whiskers.

Table I. Molten-Salt-Synthesized Samples

\begin{tabular}{llccc}
\hline Sample & \multicolumn{1}{c}{ Salt } & $\begin{array}{c}\text { Salt/HA } \\
\text { (by weight) }\end{array}$ & $\begin{array}{c}\text { Reaction temperature } \\
\left({ }^{\circ} \mathrm{C}\right)\end{array}$ & $\begin{array}{c}\text { Reaction time } \\
(\mathrm{h})\end{array}$ \\
\hline $\mathrm{W} 1$ & $\mathrm{~K}_{2} \mathrm{SO}_{4}$ & 1.2 & 1190 & 3.5 \\
W2 & $\mathrm{K}_{2} \mathrm{SO}_{4}$ & 1.2 & 1150 & 2.0 \\
W3 & $\mathrm{K}_{2} \mathrm{SO}_{4}$ & 1.2 & 1100 & 1.0 \\
W4 & $\mathrm{K}_{2} \mathrm{SO}_{4}$ & 1.6 & 1190 & 3.5 \\
W5 & $\mathrm{K}_{2} \mathrm{SO}_{4}$ & 1.6 & 1150 & 2.0 \\
W6 & $\mathrm{K}_{2} \mathrm{SO}_{4}$ & 1.6 & 1100 & 1.0 \\
W7 & $\mathrm{K}_{2} \mathrm{SO}_{4}$ & 2.4 & 1190 & 3.5 \\
W8 & $\mathrm{K}_{2} \mathrm{SO}_{4}$ & 3.0 & 1190 & 3.5 \\
W9 & $\mathrm{K}_{2} \mathrm{SO}_{4}$ & 3.0 & 1150 & 2.0 \\
W10 & $\mathrm{K}_{2} \mathrm{SO}_{4}$ & 3.0 & 1100 & 2.0 \\
W11 & $\mathrm{K}_{2} \mathrm{SO}_{4}$ & 3.0 & 1100 & 1.0 \\
W12 & $\mathrm{K}_{2} \mathrm{SO}_{4}$ & 3.0 & 1080 & 0.5 \\
P1 & $\mathrm{KCl}_{\text {C2 }}$ & 1.6 & 880 & 3.0 \\
PCl & 1.6 & 1000 & 3.0 \\
P3 & $\mathrm{KBr}_{\text {P4 }}$ & 1.6 & 850 & 3.0 \\
P5 & $\mathrm{KBr}_{2} \mathrm{Na}_{2} \mathrm{SO}_{4}$ & 1.6 & 1000 & 3.0 \\
P6 & $\mathrm{CaCl}_{2}$ & 3.0 & 1000 & 3.0 \\
P7 & $\mathrm{CaCl}_{2}$ & 3.0 & 850 & 3.0 \\
\hline
\end{tabular}

presence of $\mathrm{K}^{+}$in the lattice also has been reported previously ${ }^{30}$ to have no influence on the lattice parameters of hydroxyapatite. Therefore, a tentative XRD pattern for the HA whiskers (with the strongest XRD peak assigned to the 300, rather than the 211, plane) was created and is given in Table II.

Figures 3(a) and (b) show the SEM micrographs of molten-saltsynthesized HA whiskers of samples W1 and W4, respectively. The aspect ratios (i.e., length/diameter) varied in the range 2-18, with the median whisker diameter and length $9 \mu \mathrm{m}$ and $55 \mu \mathrm{m}$, respectively. Whiskers were monodisperse and were not fused to one another. Interestingly, samples W2, W3, and W5-W11 produced almost the same microstructures and whisker morphologies. Thus, the $\mathrm{K}_{2} \mathrm{SO}_{4}$-to-HA weight ratio (in the range 1.2-3.0), the reaction temperature (in the range $1100^{\circ}-1190^{\circ} \mathrm{C}$ ), and the reaction time (in the range $1-3.5 \mathrm{~h}$ ) were almost unable to influence the resultant HA whisker morphology. On the other hand, Fig. 3(c) shows that sample $\mathrm{W} 12$ (i.e., $1080^{\circ} \mathrm{C}, 0.5 \mathrm{~h}, \mathrm{~K}_{2} \mathrm{SO}_{4}$-to-HA weight ratio $=3.0$ ) exhibited the formation of monodisperse, but much thinner, HA whiskers, with an aspect ratio $>30$ and a typical diameter and length of $2 \mu \mathrm{m}$ and $65 \mu \mathrm{m}$, respectively. The XRD

Table II. Experimental XRD Pattern of HA Whiskers ${ }^{\dagger}$

\begin{tabular}{|c|c|c|c|}
\hline $2 \theta$ & $d(\AA)$ & $h k l$ & $I / I_{0}$ \\
\hline 10.8335 & 8.1600 & 100 & 8 \\
\hline 16.8416 & 5.2601 & 101 & 4 \\
\hline 18.8287 & 4.7092 & 110 & 3 \\
\hline 21.7654 & 4.0800 & 200 & 9 \\
\hline 22.8615 & 3.8868 & 111 & 8 \\
\hline 25.8647 & 3.4419 & 002 & 7 \\
\hline 28.1278 & 3.1699 & 102 & 2 \\
\hline 28.9355 & 3.0832 & 210 & 8 \\
\hline 31.7870 & 2.8128 & 211 & 26 \\
\hline 32.1873 & 2.7788 & 112 & 13 \\
\hline 32.9093 & 2.7194 & 300 & 100 \\
\hline 34.0553 & 2.6305 & 202 & 12 \\
\hline 35.4751 & 2.5284 & 301 & 3 \\
\hline 39.1983 & 2.2964 & 212 & 3 \\
\hline 39.8151 & 2.2622 & 310 & 18 \\
\hline 42.0046 & 2.1492 & 311 & 2 \\
\hline 42.3272 & 2.1336 & 302 & 3 \\
\hline 43.8628 & 2.0624 & 113 & 6 \\
\hline 44.3859 & 2.0393 & 400 & 3 \\
\hline 45.3132 & 1.9997 & 203 & 2 \\
\hline 46.7025 & 1.9434 & 222 & 9 \\
\hline 48.0899 & 1.8905 & 312 & 4 \\
\hline 48.6156 & 1.8713 & 320 & 3 \\
\hline 49.4793 & 1.8406 & 213 & 9 \\
\hline 50.5031 & 1.8057 & 321 & 6 \\
\hline 51.2834 & 1.7800 & 410 & 9 \\
\hline 52.0951 & 1.7542 & 402 & 4 \\
\hline 53.1910 & 1.7206 & 004 & 3 \\
\hline 54.4593 & 1.6835 & 104 & 2 \\
\hline 55.8807 & 1.6440 & 322 & 7 \\
\hline 57.1331 & 1.6109 & 313 & 5 \\
\hline 58.0628 & 1.5873 & 501 & 2 \\
\hline 59.9570 & 1.5416 & 420 & 3 \\
\hline 60.4326 & 1.5306 & 331 & 3 \\
\hline 61.6848 & 1.5025 & 214 & 7 \\
\hline 63.0029 & 1.4742 & 502 & 8 \\
\hline 63.4444 & 1.4650 & 510 & 2 \\
\hline 64.1687 & 1.4502 & 323 & 9 \\
\hline 65.0382 & 1.4329 & 511 & 6 \\
\hline 66.3987 & 1.4068 & 422 & 2 \\
\hline 69.7071 & 1.3479 & 512 & 1 \\
\hline
\end{tabular}

${ }^{\dagger}$ For W4 at $1190^{\circ} \mathrm{C}$. 

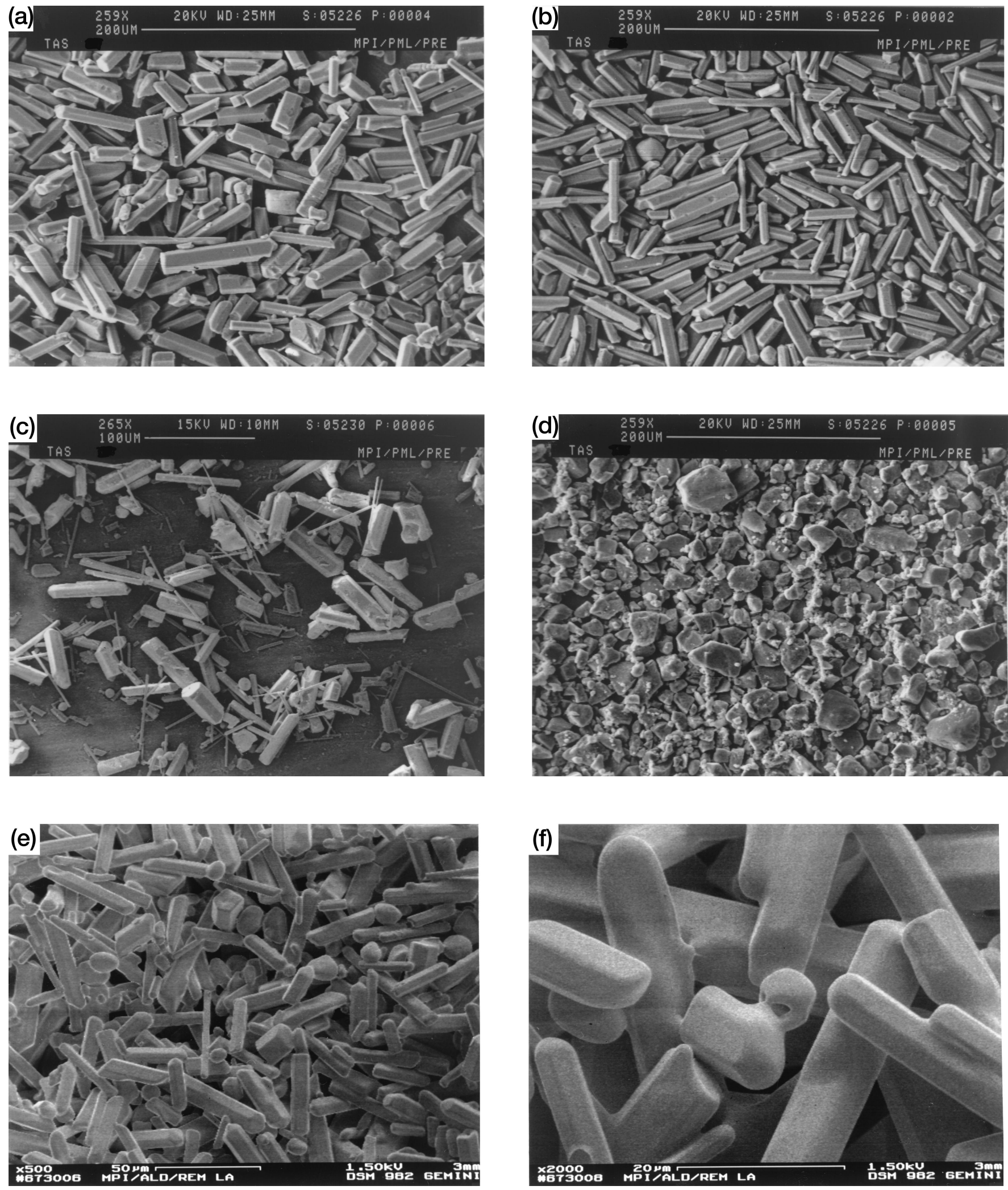

Fig. 3. SEM micrographs of HA whiskers and crystals: (a) W1, (b) W4, (c) W12, (d) P1, (e) and (f) W4 at $1300^{\circ} \mathrm{C}$ (see Table I for sample designations).

pattern of this sample again showed the presence of calcium hydroxyapatite only.

The above set of experimental data, obtained using $\mathrm{K}_{2} \mathrm{SO}_{4}$ as the fluxing agent, implies the following process:

(1) The liquid phase formed during the MSS process by the molten $\mathrm{K}_{2} \mathrm{SO}_{4}$ (i.e., the flux) first dissolves all of the initial ceramic raw material.

(2) With further heating, particles of the apatite phase are formed through the nucleation and growth processes. ${ }^{16}$
(3) As the molten ionic bath cools, while passing through its melting point down to room temperature, rapid crystallization occurs along the preferred growth axes of the ceramic phase.

(4) HA whisker growth occurs during MSS, by a sequential "dissolution-crystallization-whisker-growth" process.

(5) Solubility of the ceramic raw material in the molten flux (which is a function of temperature) must have a significant role in the crystallization process to follow. 


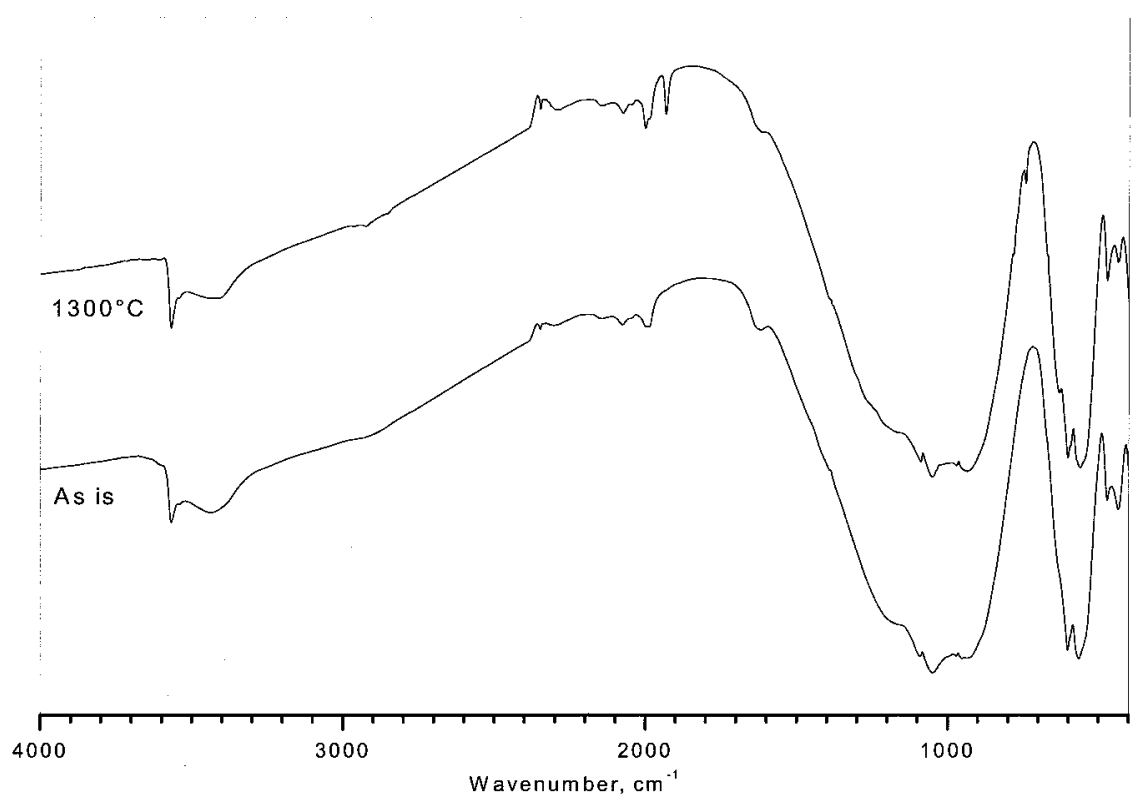

Fig. 4. FT-IR spectra (transmittance) of HA whiskers.

(6) The extent of superheating of the molten flux must also have a rather strong effect on the resultant aspect ratio of the formed whiskers (as evidenced by the case of sample W12).

(7) The morphology of the whiskers growing out of the cooling molten salt bath must be strongly dependent on soaking time at the peak temperature.

Whiskers with the highest aspect ratio were obtained at the lowest temperature and time combination, i.e., sample W12 of Table I, a result suggesting that time and temperature are the most significant variables in altering the whisker morphology, along with the use of an appropriate fluxing agent, in which the ceramic raw material has sufficient solubility.

To test the feasibility of decreasing the MSS temperature, we also tried using $\mathrm{KCl}, \mathrm{KBr}, \mathrm{Na}_{2} \mathrm{SO}_{4}$, and $\mathrm{CaCl}_{2}$, rather than $\mathrm{K}_{2} \mathrm{SO}_{4}$, with the MSS parameters given in Table I. These samples were labeled P1-P7. Interestingly, none of the samples were able to produce HA whiskers, and the reason(s) for this failure may also be found in the above paragraph. Figure 3(d) shows the SEM micrograph of the P1 powders, and this morphology was also encountered with the other samples, P2-P7. The product phase in all of these P $x$ samples was, again, calcium hydroxyapatite, with an average particle size of $25 \mu \mathrm{m}$. The finer portion of the powder body (of Fig. 3(d)) is believed to have been the undissolved, initial HA powder, and the larger portion consisted of single crystals of HA. Such hydroxyapatite powders, with a large average particle size, may be useful for applications such as plasma-spraying. However, ICP-AES analyses performed on the $\mathrm{P} 1$ and $\mathrm{P} 2$ samples indicated the presence of chlorine (in the range $1.5 \%-1.7 \%$ ) in the final powders. It can be inferred that using $\mathrm{KCl}$ as the molten salt facilitates at least the partial transformation of hydroxyapatite into chloroapatite.

Figures 3(e) and (f) show the microstructures of W4 whiskers at two different magnifications, after heating as loose powder compacts in alumina boats, at $1300^{\circ} \mathrm{C}$, for $9 \mathrm{~h}$ in a stagnant air atmosphere. For the molten-salt-synthesized HA whiskers of the present study, the previously mentioned problem (for the whiskers synthesized by the hydrothermal method) ${ }^{3-6}$ of morphologic degradation apparently was not present. The W4 whiskers retained their shapes perfectly, formed a skeleton of HA, and just fused together at the points of mutual contact. However, the XRD pattern of the whiskers heated at $1300^{\circ} \mathrm{C}$ (see Fig. 2) showed the presence of a second phase of $\alpha$-TCP (ICDD No. PDF 9-348*), the

*Powder Diffraction File, No. PDF 9-348. International Centre for Diffraction Data, Newtown Square, PA. high-temperature orthorhombic polymorph of tricalcium phosphate, $\mathrm{Ca}_{3}\left(\mathrm{PO}_{4}\right)_{2}$. The formation of TCP, as a decomposition product of $\mathrm{HA}$, in samples heated at $1300^{\circ} \mathrm{C}$ in an air atmosphere, is well-known and normal. ${ }^{1,30}$ Previous reports ${ }^{31}$ have also noted that, for synthetic hydroxyapatites cooled rapidly (as in the present study) from temperatures $>1250^{\circ} \mathrm{C}$, the crystallographic form of TCP observed will always be the high-temperature polymorph.

The FT-IR spectrum of the as-synthesized W4 whiskers shown in the bottom trace of Fig. 4 is characteristic for calcium hydroxyapatite. All bands originating from $\mathrm{PO}_{4}$ and $\mathrm{OH}$ groups are clearly visible. The absence of any distinct bands in the range $1500-1400 \mathrm{~cm}^{-1}$ means that the HA whiskers do not contain significant quantities of carbonate ions. ${ }^{32}$ Bands in the region $1190-975 \mathrm{~cm}^{-1}$ result from the $v_{3}$ vibrational mode of the phosphate group. A phosphate $v_{1}$ band is present at $\sim 962 \mathrm{~cm}^{-1}$. A phosphate $v_{4}$ band is present in the region $605-560 \mathrm{~cm}^{-1}$, and two sites are observed for these whiskers at 602 and $569 \mathrm{~cm}^{-1}$. A phosphate vibration, $v_{2}$, is observed in the form of two discrete peaks at 471 and $433 \mathrm{~cm}^{-1}$. The $\mathrm{OH}$ vibrations at 3571 $\mathrm{cm}^{-1}$ (stretching) and $634 \mathrm{~cm}^{-1}$ (bending) are well-defined, and the band in the region $1638-1600 \mathrm{~cm}^{-1}$ is a result of $\mathrm{H}-\mathrm{O}-\mathrm{H}$ deformation. Atmospheric $\mathrm{CO}_{2}$ is indicated by the band at $2349 \mathrm{~cm}^{-1}$.

The infrared spectrum of the W4 whiskers calcined in air at $1300^{\circ} \mathrm{C}$ for $9 \mathrm{~h}$ (depicted by the top trace in Fig. 4) shows, as well as all of the above-mentioned bands, a unique band at $743 \mathrm{~cm}^{-1}$, which is characteristic of the $\mathrm{P}-\mathrm{O}-\mathrm{P}$ vibrational mode of pyrophosphates, ${ }^{32}$ although their XRD patterns did not indicate the presence of $\mathrm{Ca}_{2} \mathrm{P}_{2} \mathrm{O}_{7}$ as a decomposition product. The band at $1933 \mathrm{~cm}^{-1}$ could not be identified.

Biocompatible HA whiskers prepared by the MSS technique could be useful for numerous applications involving the reinforcement of hydroxyapatite-based bioceramics. As shown in this report, the MSS process for calcium hydroxyapatite whisker manufacture is quite robust, because it does not require the achievement of precise, up-to-the-last-digit control over many of the processing parameters, such as the flux-to-HA ratio, reaction temperature, and time.

\section{Summary}

Molten salt synthesis (MSS) of monodisperse calcium hydroxyapatite whiskers was accomplished using a $\mathrm{K}_{2} \mathrm{SO}_{4}$ flux. Singlephase, potassium-doped HA whiskers proved possible to synthesize over the temperature range $1080^{\circ}-1190^{\circ} \mathrm{C}$, and the $\mathrm{K}_{2} \mathrm{SO}_{4}$ to-HA ratios in the initial mixtures could be varied between 1.2 and 3.0 without significantly affecting the whisker morphology. 
HA whiskers produced by the $\mathrm{K}_{2} \mathrm{SO}_{4}$ flux retained their initial shapes and aspect ratios, even after heating in air at $1300^{\circ} \mathrm{C}$ for $9 \mathrm{~h}$, although they started to decompose into TCP. Fluxing agents such as $\mathrm{KCl}, \mathrm{KBr}, \mathrm{CaCl}_{2}$, and $\mathrm{Na}_{2} \mathrm{SO}_{4}$, when used in place of $\mathrm{K}_{2} \mathrm{SO}_{4}$, produced large single crystals of $\mathrm{HA}$, with an average particle size of $25 \mu \mathrm{m}$, rather than whiskers, over the MSS temperature range $850^{\circ}-1000^{\circ} \mathrm{C}$.

\section{Acknowledgments}

The author gratefully acknowledges the Max-Planck-Institut für Metallforschung, Stuttgart, Germany, for the award of Visiting Professorship, from February 1999 to February 2001. The author also expresses his personal appreciation to H. Labitzke (SEM), F. Predel (SEM/EDS), G. Kaiser (ICP-AES), M. Thomas (XRD), and W. König (FT-IR) of MPI for their help with sample characterization.

\section{References}

${ }^{1}$ L. L. Hench, "Bioceramics: From Concept to Clinic," J. Am. Ceram. Soc., 74, 1487-510 (1991).

${ }^{2}$ L. Yubao, K. De Groot, J. De Wijn, C. P. A. T. Klein, and S. V. D. Meer, "Morphology and Composition of Nanograde Calcium Phosphate Needle-like Crystals Formed by Simple Hydrothermal Method," J. Mater. Sci.: Mater. Med., 5, 326-31 (1994).

${ }^{3}$ M. Yoshimura, H. Suda, K. Okamoto, and K. Ioku, "Hydrothermal Synthesis of Biocompatible Whiskers," J. Mater. Sci., 29, 3399-402 (1994).

${ }^{4}$ W. Suchanek, H. Suda, M. Yashima, M. Kakihana, and M. Yoshimura, "Biocompatible Whiskers with Controlled Morphology and Stoichiometry," J. Mater. Res., 10, 521-29 (1995).

${ }^{5}$ W. Suchanek, M. Yashima, M. Kakihana, and M. Yoshimura, "Hydroxyapatite/ Hydroxyapatite-Whisker Composites without Sintering Additives: Mechanical Properties and Microstructural Evolution," J. Am. Ceram. Soc., 80, 2805-13 (1997).

${ }^{6}$ W. L. Suchanek and M. Yoshimura, "Preparation of Fibrous, Porous Hydroxyapatite Ceramics from Hydroxyapatite Whiskers," J. Am. Ceram. Soc., 81, 765-67 (1998).

${ }^{7}$ T. Iizuka and A. Nozuma, "Effects of $\mathrm{pH}$ of the Aqueous Solutions on the Growth of Hydroxyapatite Whiskers," J. Ceram. Soc. Jpn., 106, 820-23 (1998).

${ }^{8}$ T. Iizuka and A. Nozuma, "Effects of the Buffer Solutions on the Growth of Hydroxyapatite Whiskers," J. Ceram. Soc. Jpn., 107, 442-48 (1999).

${ }^{9}$ A. Nakahira, K. Sakamoto, S. Yamaguchi, M. Kaneno, S. Takeda, and M. Okazaki, "Novel Synthesis Method of Hydroxyapatite Whiskers by Hydrolysis of $\alpha$-Tricalcium Phosphate in Mixtures of Water and Organic Solvent," J. Am. Ceram. Soc., 82, 2029-32 (1999).

${ }^{10} \mathrm{R}$. H. Arendt, "The Molten Salt Synthesis of Single Magnetic Domain $\mathrm{BaFe}_{12} \mathrm{O}_{19}$ and $\mathrm{SrFe}_{12} \mathrm{O}_{19}$ Crystals," J. Solid State Chem., 8, 339-47 (1973).

${ }^{11}$ P. A. Fuierer and R. E. Newnham, "La $\mathrm{Ti}_{2} \mathrm{O}_{7}$ Ceramics," J. Am. Ceram. Soc., 74, 2876-81 (1991)

${ }^{12}$ A. Aboujalil, J. P. Deloume, F. Chassagneux, J. P. Scharff, and B. Durand, "Molten Salt Synthesis of the Lead Titanate $\mathrm{PbTiO}_{3}$, Investigation of the Reactivity of Various Titanium and Lead Salts with Molten Alkali-Metal Nitrites," J. Mater. Chem., 8, 1601-606 (1998).

${ }^{13}$ K. Katayama, Y. Azuma, and Y. Takahashi, "Molten Salt Synthesis of SinglePhase $\mathrm{BaNd}_{2} \mathrm{Ti}_{4} \mathrm{O}_{12}$ Powder," J. Mater. Sci., 34, 301-305 (1999).

${ }^{14}$ C. C. Li, C. C. Chiu, and S. B. Desu, "Formation of Lead Niobates in Molten Salt Systems," J. Am. Ceram. Soc., 74, 42-47 (1991).

${ }^{15}$ D. M. Wan, J. Wang, S. C. Ng, and L. M. Gan, "Formation and Characterization of Lead Magnesium Niobate Synthesized from the Molten Salt of Potassium Chlorate," J. Alloys Compd., 274, 110-17 (1998).

${ }^{16}$ K. H. Yoon, Y. S. Cho, and D. H. Kang, "Review: Molten Salt Synthesis of Lead-based Relaxors," J. Mater. Sci., 33, 2977-84 (1998).

${ }^{17}$ B. Brahmaroutu, G. L. Messing, and S. Trolier-McKinstry, "Molten Salt Synthesis of Anisotropic $\mathrm{Sr}_{2} \mathrm{Nb}_{2} \mathrm{O}_{7}$ Particles," J. Am. Ceram. Soc., 82, 1565-68 (1999).

${ }^{18}$ S. Hashimoto and A. Yamaguchi, "Synthesis of Needlelike Mullite Particles Using Potassium Sulfate Flux,” J. Eur. Ceram. Soc., 20, 397-402 (2000).

${ }^{19}$ H. Wada, K. Sakane, T. Kitamura, and H. Hata, "The Reaction Sequence in the Synthesis of Aluminum Borate Whiskers," J. Mater. Sci., 31, 537-44 (1996).

${ }^{20}$ I. E. Gonenli and A. C. Tas, "Chemical Preparation of Aluminum Borate Whiskers," Powder Diffr., 15, 104-107 (2000).

${ }^{21}$ S. Hayashi, M. Sugai, Z. Nakagawa, T. Takei, K. Kawasaki, T. Katsuyama, A. Yasumori, and K. Okada, "Preparation of $\mathrm{CaSiO}_{3}$ Whiskers from Alkali Halide Fluxes," J. Eur. Ceram. Soc., 20, 1099-103 (2000).

${ }^{22}$ Y. Suetsugu and J. Tanaka, "Crystal Growth of Carbonate Apatite Using a $\mathrm{CaCO}_{3}$ Flux," J. Mater. Sci.: Mater. Med., 10, 561-66 (1999).

${ }^{23}$ A. C. Tas, "Production of the Two Inorganic Phases $\left[\left(\mathrm{Ca}_{10}\left(\mathrm{PO}_{4}\right)_{6}(\mathrm{OH})_{2}\right.\right.$ : Calcium Hydroxyapatite and $\mathrm{Ca}_{3}\left(\mathrm{PO}_{4}\right)_{2}$ : Tri-Calcium Phosphate] of Synthetic Bones by Using a Chemical Precipitation Technique," Turk. Pat. No. TR 199501422 B, Turkish Patent Institute, Ankara, Turkey.

${ }^{24}$ A. C. Tas, F. Korkusuz, M. Timucin, and N. Akkas, "An Investigation of the Chemical Synthesis and High-Temperature Sintering Behaviour of Calcium Hydroxyapatite (HA) and Tricalcium Phosphate (TCP) Bioceramics," J. Mater. Sci.: Mater. Med., 8, 91-96 (1997).

${ }^{25}$ B. Mavis and A. C. Tas, "Dip-Coating of Calcium Hydroxyapatite on Ti-6Al-4V Substrates," J. Am. Ceram. Soc., 83, 989-91 (2000).

${ }^{26}$ E. Hayek and H. Newesely, "Pentacalcium Monohydroxyorthophosphate," Inorg. Syn., 7, 63-65 (1963)

${ }^{27}$ E. C. Moreno, T. M. Gregory, and W. E. Brown, "Preparation and Solubility of Hydroxyapatite," J. Res. Natl. Bur. Stand. (U.S.), 72A, 773-82 (1968)

${ }^{28}$ M. Jarcho, C. H. Bolen, M. B. Thomas, J. Bobick, J. P. Kay, and R. H. Doremus, "Hydroxyapatite Synthesis and Characterization in Dense Polycrystalline Form," $J$. Mater. Sci., 11, 2027-35 (1976).

${ }^{29}$ D. E. Appleman and H. T. Evans, "Indexing and Least-Squares Refinement of Powder Diffraction Data," U.S. Geol. Survey Rept. No. GD-73-003, 1973.

${ }^{30}$ R. Z. LeGeros and J. P. LeGeros, "Dense Hydroxyapatite"; pp. 139-80 in An Introduction to Bioceramics. Edited by L. L. Hench and J. Wilson. World Scientific, Singapore, Republic of Singapore, 1993.

${ }^{31}$ N. Kivrak and A. C. Tas, "Synthesis of Calcium Hydroxyapatite-Tricalcium Phosphate (HA-TCP) Composite Bioceramic Powders and Their Sintering Behavior," J. Am. Ceram. Soc., 81, 2245-52 (1998).

${ }^{32} \mathrm{~A}$. C. Tas, "Synthesis of Biomimetic Ca-Hydroxyapatite Powders at $37^{\circ} \mathrm{C}$ in Synthetic Body Fluids," Biomaterials, 21, 1429-38 (2000). 